\title{
Imagining the Dutch polder landscape: a design by OMA from 1986
}

\section{Christophe Van Gerrewey}

To cite this article: Christophe Van Gerrewey (2015) Imagining the Dutch polder landscape: a design by OMA from 1986, Journal of Landscape Architecture, 10:3, 20-27, DOI: 10.1080/18626033.2015.1094900

To link to this article: http://dx.doi.org/10.1080/18626033.2015.1094900

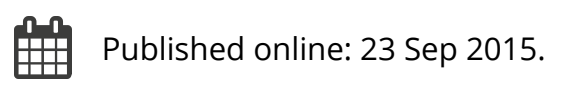

Submit your article to this journal ๘

\section{Џll Article views: 3}

\section{Q View related articles $\sqsubset$}

$$
\text { View Crossmark data ¿ }
$$




\section{Imagining the Dutch polder landscape: a design by OMA from 1986}

\section{Abstract}

In 1986, the Office for Metropolitan Architecture (OMA) / Rem Koolhaas created a landscape design for the Haarlemmermeerpolder, located between Amsterdam, Leiden, and Haarlem. They were invited by urbanists and planners wanting to denounce the urban policy in the 1980s. Dutch spatial development, once characterized by reclamation and bold city planning, had come to a standstill.

The possible urbanity of the Haarlemmermeerpolder-a unity based on differences and incongruences - can be considered the spatial and ideological blueprint behind that decade's more famous designs by OMA. While the project for the Haarlemmermeerpolder seems to present a modernization of agriculture, it is one of the few instances in which a past, present, and future image of the Dutch polder landscape was created. OMA reconciles the desire for ground-breaking and large-scale public projects with a diversified society, an immaterial economy, and a political system that seems to sabotage the possibility of a consciously created landscape.

exhibition Nieuw Nederland 2050 / Haarlemmermeerpolder / $\mathrm{OMA}$ / Parc de la Villette / regional planning
Introduction: OMA and the Haarlemmermeerpolder

In 1986, Rem Koolhaas and OMA made a design for the Haarlemmermeerpolder, a large site in the heart of the Netherlands, with a complex and emblematic history. This polder, almost 200 square kilometres in size, was, until the nineteenth century, the largest Dutch lake, nicknamed the 'Waterwolf'due to its wild character. [1] In 1837, King Willem I decided on the dry milling of the lake. In 1855, Haarlemmermeer became a municipality, surrounded by a canal, the Ringvaart, and traversed, northeast to southwest, by another canal, the Hoofdvaart. The area was parceled in a grid structure: every two kilometers, there is a road, and between every two roads lies another canal. The parcels were sold to rich inhabitants from the surrounding cities who leased the land to farmers from all over of the country. In the twentieth century, horticulture was introduced, and residential settlements were urbanized: Nieuw-Vennep, in the south, and Hoofddorp, in the middle. The extension of the military airbase Schiphol, in the northeast, was defining. [2] In 1949, Schiphol became the primary Dutch airport, causing the advent of many industrial and office zones.

The history of the Haarlemmermeerpolder-its artificial grid, its past as an agricultural area, the proximity of the main Dutch cities, and the everincreasing presence of Schiphol Airport-is primordial in OMA's design from 1986. This project is a product of the relationship between politics, society, and landscape in the eighties, and it illustrates the strategic position of OMA towards these issues. As such, it can shed new light on canonical OMA projects from this era. 
Nieuw Nederland 2050: the polder model

The project for the Haarlemmermeer was made on the occasion of a large thematic exhibition, shown in 1987 in Amsterdam, entitled Nieuw Nederland 2050 (New Netherlands 2050). Four long-term scenarios for 2050 were presented to a wide audience in huge, colourful maps and models. The exhibition was the initiative of Nederland Nu als Ontwerp (NNAO) (The Netherlands Now as Design), founded in 1984 and chaired by urbanist Dirk Frieling. In the 1970s, Frieling was head of the project office that developed the new town Almere, capital of Flevoland-a widespread polderdeveloped in 1968 and the largest artificial island in the world. [3]

The impetus behind the NNAO was the protest against the conviction, omnipresent in policy circles in the mid-1980s, that the Netherlands was 'finished' as a spatially ordered society: no more expensive urban planning was needed. A group of individuals-members of the last generation of hard-core urban planners-wanted to denounce the disinterest of the government in the development of the Dutch territory, once known for its dauntless, progressive, and literally ground-breaking activities. Their criticism was directed at the standstill in a country that had created 4,000 polders by reclaiming marshes and fenland.

Ironically enough, the political model that NNAO was hackling is exactly called the polder model-the Dutch version of consensus-based economic and social policy making of the 1980 s and 1990s. In a recent reassessment in Low Countries Historical Review, Joost Jonker has summarized the polder model as follows: 'Endless rounds of meetings are not everybody's ideal of efficient decision-making: but since the 1982 tripartite agreement on macro-economic policy between the Dutch government, employers' organizations and the labor unions, institutionalized talks are considered the warp and the weft of the country's social fabric and the key to its economic success. [...] In a curious transposition of a stereotype formerly favored only by tourists, the terms "polderen" or "polder model" for such processes betray their presumed origin, the need to weld very different social groups together in the country's running battle against flooding' (Jonker 2014: 88). The historical process of regaining land from the sea, requiring constant pumping and maintenance of dykes, forced conflicting parts of society to cooperate. In a similar fashion, at the end of twentieth century, the 'red' social-democratic party and the 'blue' rightwing economic liberals tried to reconcile their differences by means of a 'purple' government. For NNAO, it was this pragmatic and bureaucratic policy that thwarted future-oriented urban projects: 'The initiators of this project utilize actuality to give a solution-oriented kick in the behind of a problem-oriented society. [...] High and low, people are prepared to promote the public cause. But it seems society is controlled by paralysis. There is an urgent need for an impulse to liberate us from this paralysis. An incentive for movement' (Van Cammen 1987: 10, 16).
To avoid weak compromises, the strategies developed by NNAO in 1987 were based on clear-cut, not to say caricatured ideologies. As Christian Salewski has written in his book on Dutch spatial planning at the end of the twentieth century, 'the scenarios [of NNAO] should show how different political choices would lead to very different spatial structures. [...] Each scenario was linked to a Dutch political party: "Careful Netherlands" was a technocratic-confessional scenario associated with the Christian-Democrats; "Critical Netherlands" as a sociocratic / socialist scenario linked with the Social-Democrats; and "Dynamic Netherlands", the technocratic scenario situated in a more right-wing corner, regarded as in line with the Liberal Party. The fourth scenario, "Relaxed Netherlands", was not paired with any party, even though [...] it was in many aspects a SocialLiberal scenario' (Salewski 2010: 224).

To summarize: no 'poldered purple', but pure and clear orange, red, and blue. Each of these scenarios-careful, dynamic, critical, and relaxedwas defined in a matrix by four characteristics: attitude towards technological progress, development of the production system, development of the rural areas, and relation between humans and environment. Based on this multifaceted concept, thirty-five designs were made, seven per category: a national spatial plan (1:250.000), a regional spatial plan (1:50.000), public amenities, agriculture, water / recreation area and water management, transport, energy, and housing.

\section{Different programmes in a stable scenical image}

The frustration inherent to the project of NNAO was not unknown to OMA. Since the mid-1980s, Koolhaas had expressed his distaste for a focus on the historical city centre, claiming that the non-urban periphery should concern architects and urban planners as a larger and urgent field of work. [4] The architects of OMA were part of a generation that looked back both nostalgically and critically on the days when the Dutch landscape was under construction. In 1993, for example, 'Point City / South City' was developed-a 'project for redesigning Holland'. It was included in 1995 in S,M,L,XL, entitled 'Unlearning Holland' and was introduced by a tirade against the spatial status quo: 'The country that more than any other has fabricated itself now treats its territory as if it has the authenticity and inevitability of nature. [...] It is crucial that the tradition of reinvention, which may be the most fertile, progressive Dutch tradition, is itself reinvented' (Koolhaas 1995: 888). The models for Holland OMA came up with, were different from each other, and just like in the case of NNAO, they were based on 'the reintroduction of explicit ideological choices' (Koolhaas 1995: 891).

Although OMA was asked in 1986 to develop the Haarlemmermeerpolder as an 'agricultural area' within the 'dynamic'-in other words, tech- 


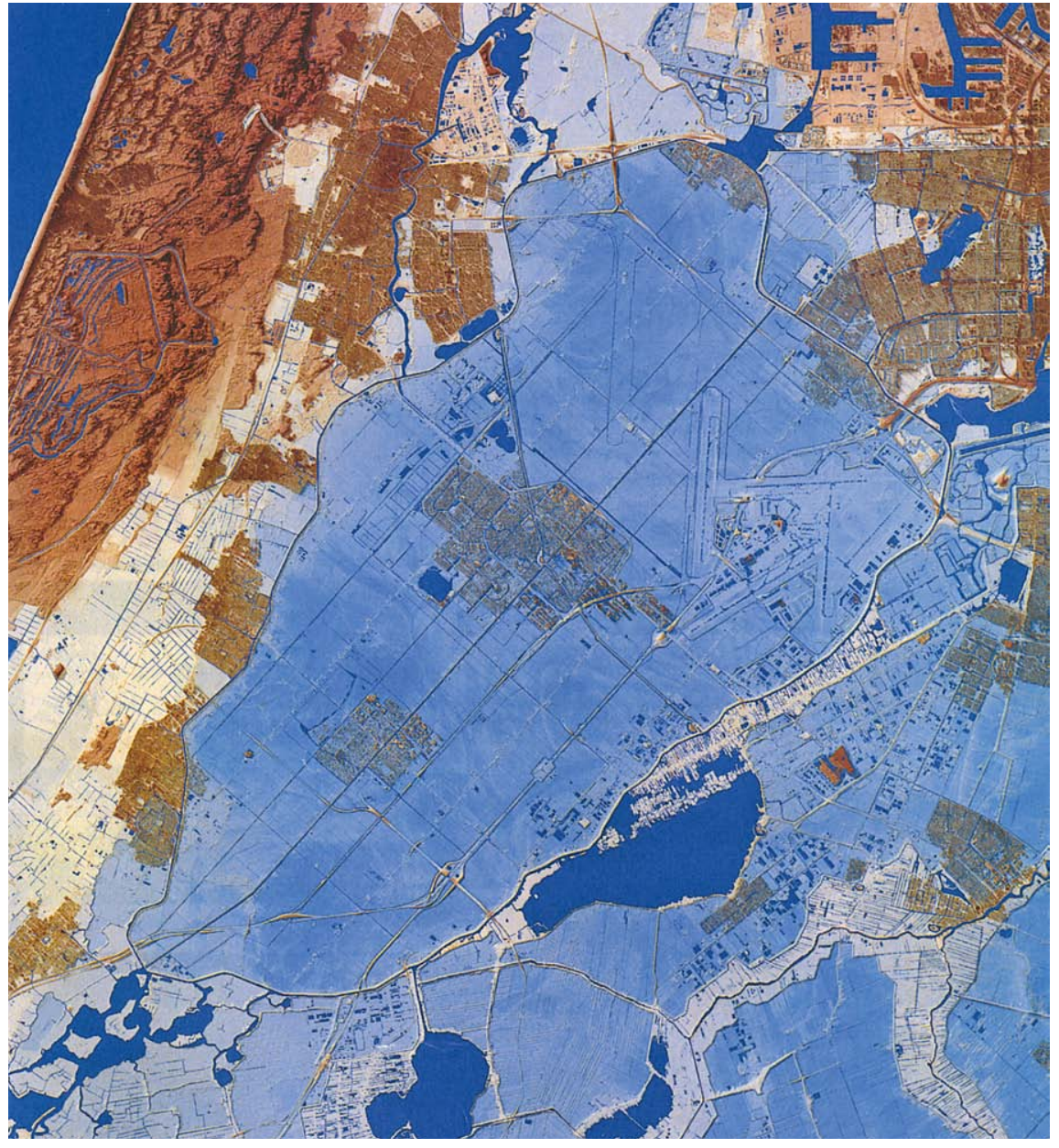

Figure 1 Map Haarlemmermeerpolder, The Netherlands ('The Polder Atlas of the Netherlands', Bussum: Thoth, 2009) nocratic-scenario, the office projected its own spatial and programmatic obsessions on the site. In a letter to NNAO, dated 20 August 1986 and reproduced in the 1987 exhibition catalogue, Koolhaas and his team explained their choice. 'We are very interested in the testing of different organizational and programmatic forms on a future area. What is at stake is the designing of structures in which the freedom for a diversity of architectonic cultures is demarcated, rather then elaborations in one architectonic style. [...] One of the qualities of the Dutch polder landscape is the fact that because of its rational parceling, it is a very suitable subsoil to harbor different programs, while it possesses, at the same time, a quite stable characteristic scenical image. [...] You can see at our studies, that we are certainly able to generate a sharp visual image of different developments' (Van Cammen 1987: 37).

The Haarlemmermeerpolder was taken on by OMA as a ready-made grid-a remnant of the pioneering past of the Netherlands, left to its own fate since its conception in the nineteenth century, that could be retroactively projected into an urban future. In another instance of retroactivity, the landscape designs of OMA from this era-such as the famous Parisian threesome Parc de la Villette (1982), Exposition Universelle (1983), and Melun-Sénart (1987)—were already present in the historical Haarlemmermeerpolder: a clearly-defined area with a rigid grid-like structure, mostly unhindered by architecture; an amalgamation of contradictory programmatic elements; and a set of empty landscape elements asking for preservation and articulation. Koolhaas has often emphasized the attachment between, for example, the design for La Villette and the city of New York. In general, the projects of OMA, certainly in the 1980s, have been interpreted and heralded as the polemical import of American modernity in the European continent (and as such as the trying out of the theses of Koolhaas' 1978 book Delirious New York. A Retroactive Manifesto for New York on foreign soil). [5] On the competition for Parc de la Villette in 1982, Koolhaas wrote in 1985: 'At la Villette, it seemed as if all conditions were there to allow an investigation in the potentialities of a metropolitan architecture in Europe: an empty field between the historical city- "violated" by the incessant demands of the 2oth century-and the plankton of suburbia' [6] (Koolhaas 1985: 15).

A glance at a map from the polder area (Fig. 1), immediately shows it: these conditions (emptiness, the vicinity of historical cities, the isolated but overwhelming presence of twentieth-century innovations, the suburban sprawl) for a research of a European modernity, were present at the Haarlemmermeerpolder-a landscape full of contrasts waiting to be revealed. As Kees Christiaanse, project architect for the OMA design in 1986, has suggested in a conversation with Salewski, the Dutch polder system can be considered as the forgotten main influence behind many OMA landscape designs from the 1980 (Salewski 2010: 272). What these projects have in common is the desire to do something that is seemingly impossible: establishing unity and coherence without eradicating differences and incongruences. The landscape is bordered and ordered, but within this order and these borders an absurd juxtaposition of activities, elements, and 

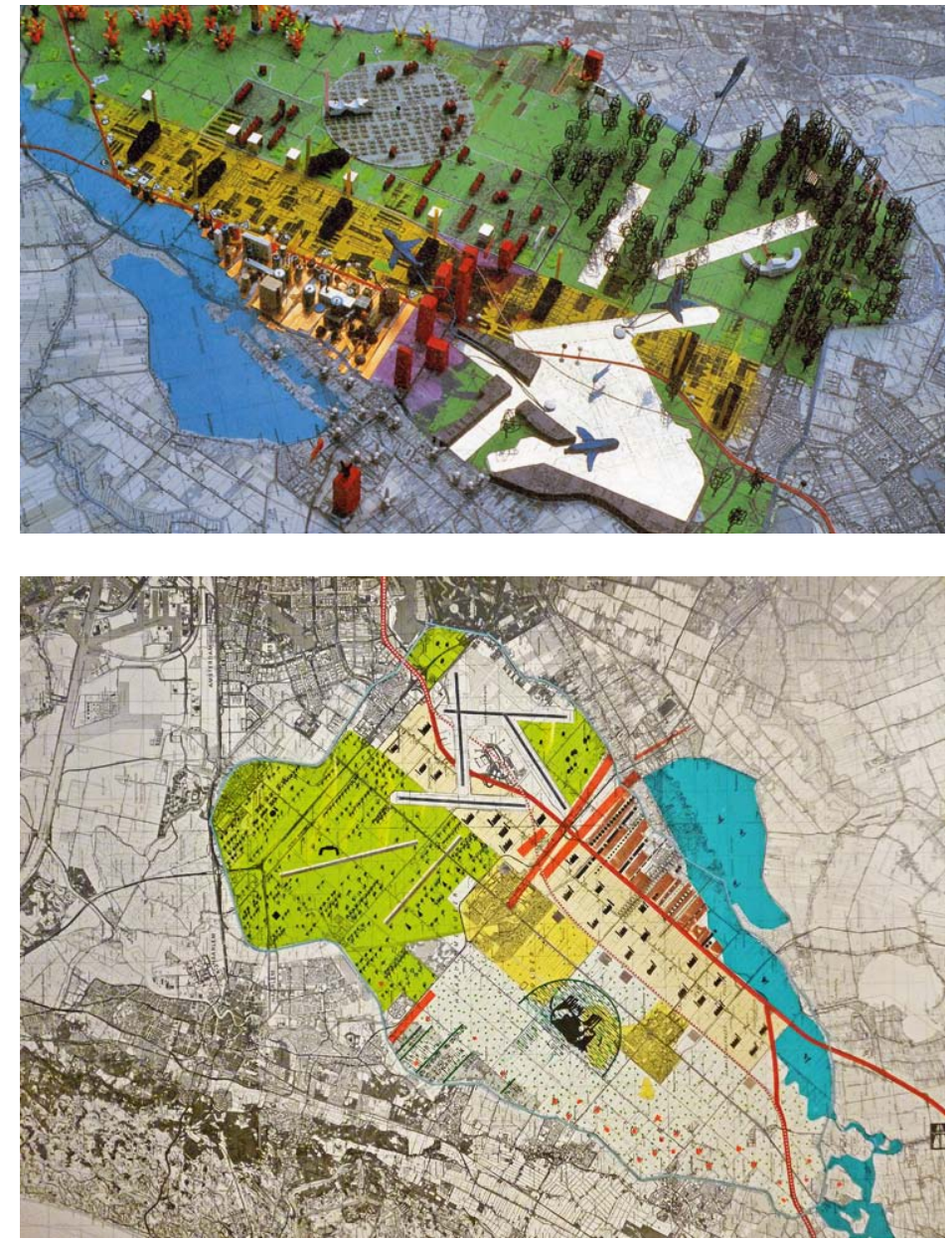

buildings emerge. In a wrongfully forgotten commentary on the OMA design for Parc de la Villette, Françoise Choay, member of the jury and OMA advocate, has stressed this: what Koolhaas did in 1982 with his design, was answering the almost impossible wishes of the French government, that had projected on the La Villette site an 'over-inflated', 'over-constraining', and 'contradictory' programme [7] These wishes therefore, Choay wrote, 'explicitly appeal to magic when invoking (postulating) a structure that would prevent the park from "becoming a hotchpotch of diverse objects"'(Choay 1985: 213). This 'magic' is also performed by OMA in the similar design for the Exposition Universelle (commissioned after the La Villette competition), and in the project for Melun-Sénart. In this design, made simultaneously with the one for the Haarlemmermeerpolder, the creation of a new city close to Paris is combined with the preservation of nature and emptiness by means of horizontal and vertical strips, resulting in what Koolhaas called 'a Chinese ideogram' (Lucan 1990: 86). Here too, there is a unity, an image, a landscape, but how it should be read, or what kind of singular meaning it can have, remains unknowable.

The contribution by OMA in 1986 to the exhibition Nieuw Nederland 2050 was in this manner another occasion to 'generate a sharp visual image of different developments'. But what this project shows, more than the other ones from the 1980s, is how the technique of a unity based on differences evolved out of the desire for progressive landscape design, in an era in which political compromises and social differentiation had made spatial development impossible.

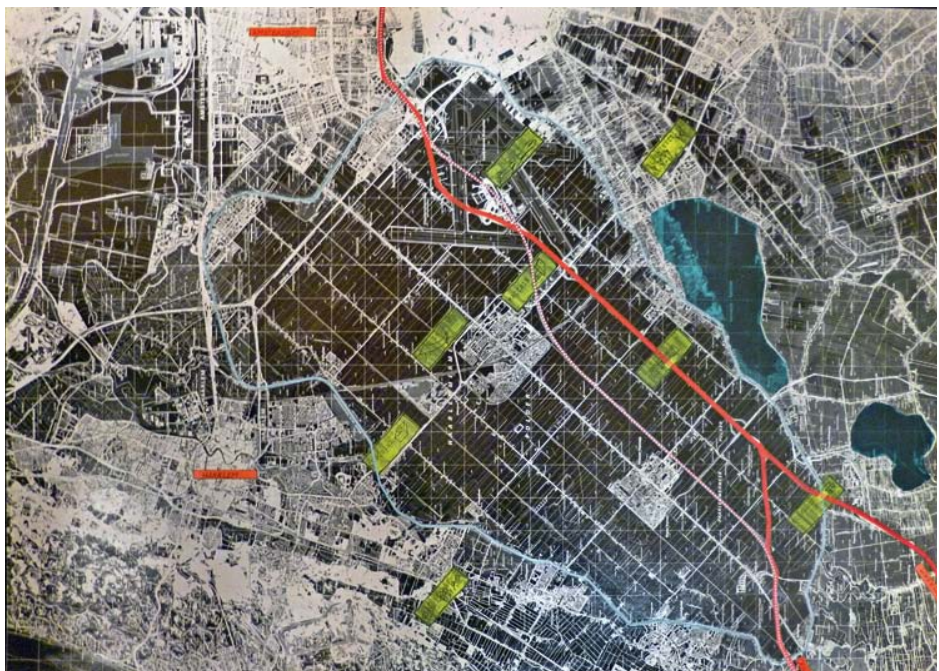

Figure 2 top left, OMA / Rem Koolhaas: Haarlemmermeerpolder, 1986 (model, OMAR-NAi, Rotterdam; below: Schiphol)

Figure 3 bottom left, OMA / Rem Koolhaas: Haarlemmermeerpolder, 1986 (map, OMAR-NAi, Rotterdam)

Figure 4 top right, OMA / Rem Koolhaas: Haarlemmermeerpolder, 1986 (map, OMAR-NAi, Rotterdam)

Imagining a Dutch polder landscape

The OMA project for the Haarlemmermeerpolder from 1987 has only partially been published in the NNAO exhibition catalogue. As archival material shows, it consists of a model, four maps, about ten collages, and five diagrams.

The design is developed along four organizational patterns, based on the existing situation: the (semi-)urban settlements are clustered; the grid of the parceling is intensely diversified; the transport lines are reinforced; and horizontal strips are organized perpendicular to the transport lines. The model and the plans are quite clear (Figs. 2-4): only the western half of the polder is developed as a green or rural area. The circular forestry of the project for La Villette reappears, a 'confetti' of historical manors is allowed to stay, and there is enough space left for future runways for Schiphol airport. The southern part of this area is reserved for 'flower tourism', as small colourful models show. At the west side of the highway (leading from Rotterdam to Schiphol and Amsterdam), large-scale production complexes arise: in the supposition that agricultural production will take place elsewhere (the project note mentions 'range cows in Argentina'), only indoor culture remains. At the eastside of the highway, joining the airport's freight centre and continuing to the outskirts of Amsterdam, a new Silicon Valley arises, with mostly factories and high-rise office buildings. This employment zone is contrasted with the Westeinderplassenan existing recreational area for swimming, sailing, surfing, and rowing, with many small islands. This area is extended, in the OMA project, by the inundation of the southeast border of the Haarlemmermeerpolder with freshwater, making specific forms of fish farming, vegetation, and recreation possible. 


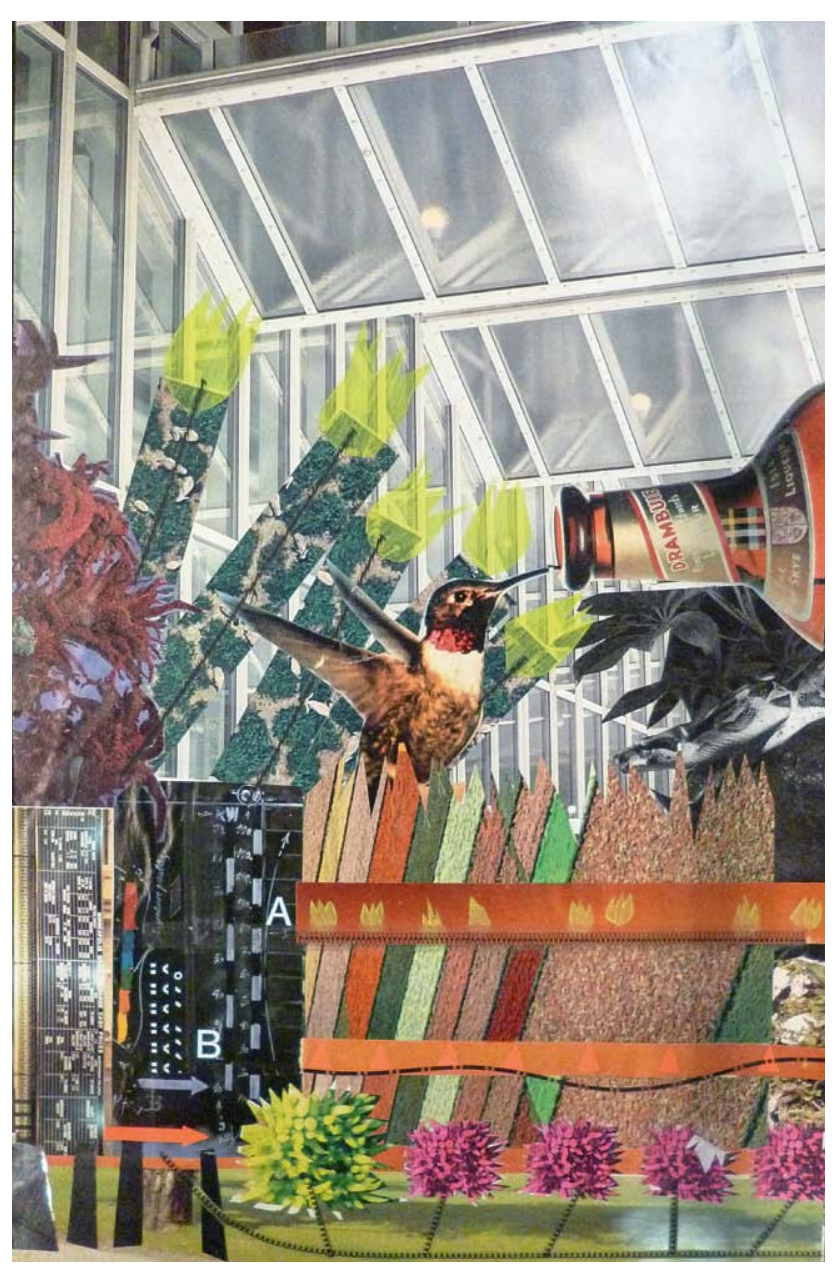

Figure 5 OMA / Rem Koolhaas: Haarlemmermeerpolder, 1986: "Indoor agriculture" (OMAR-NAi, Rotterdam)

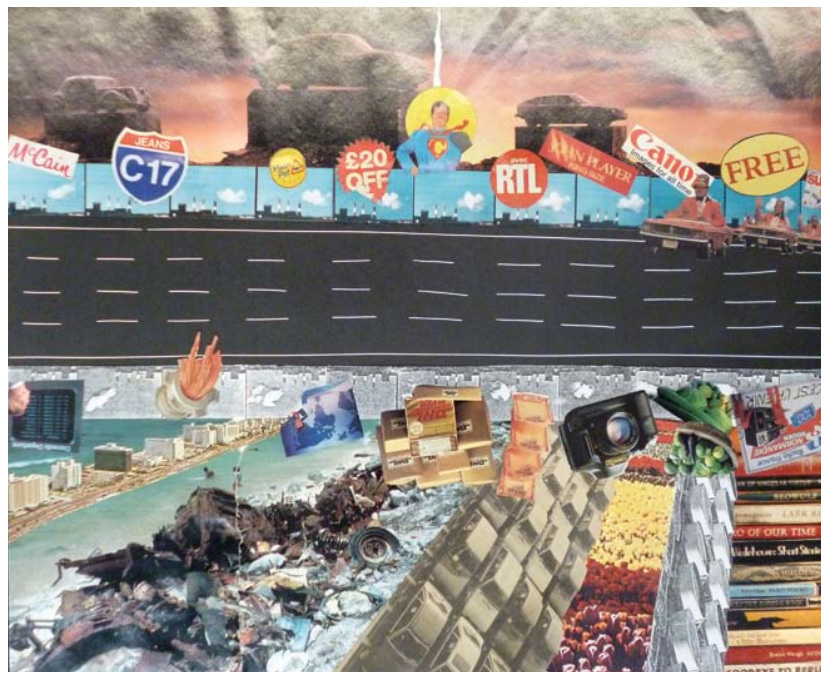

Figure 7 OMA / Rem Koolhaas: Haarlemmermeerpolder, 1986: "The road to Amsterdam" (collage, OMAR-NAi, Rotterdam)

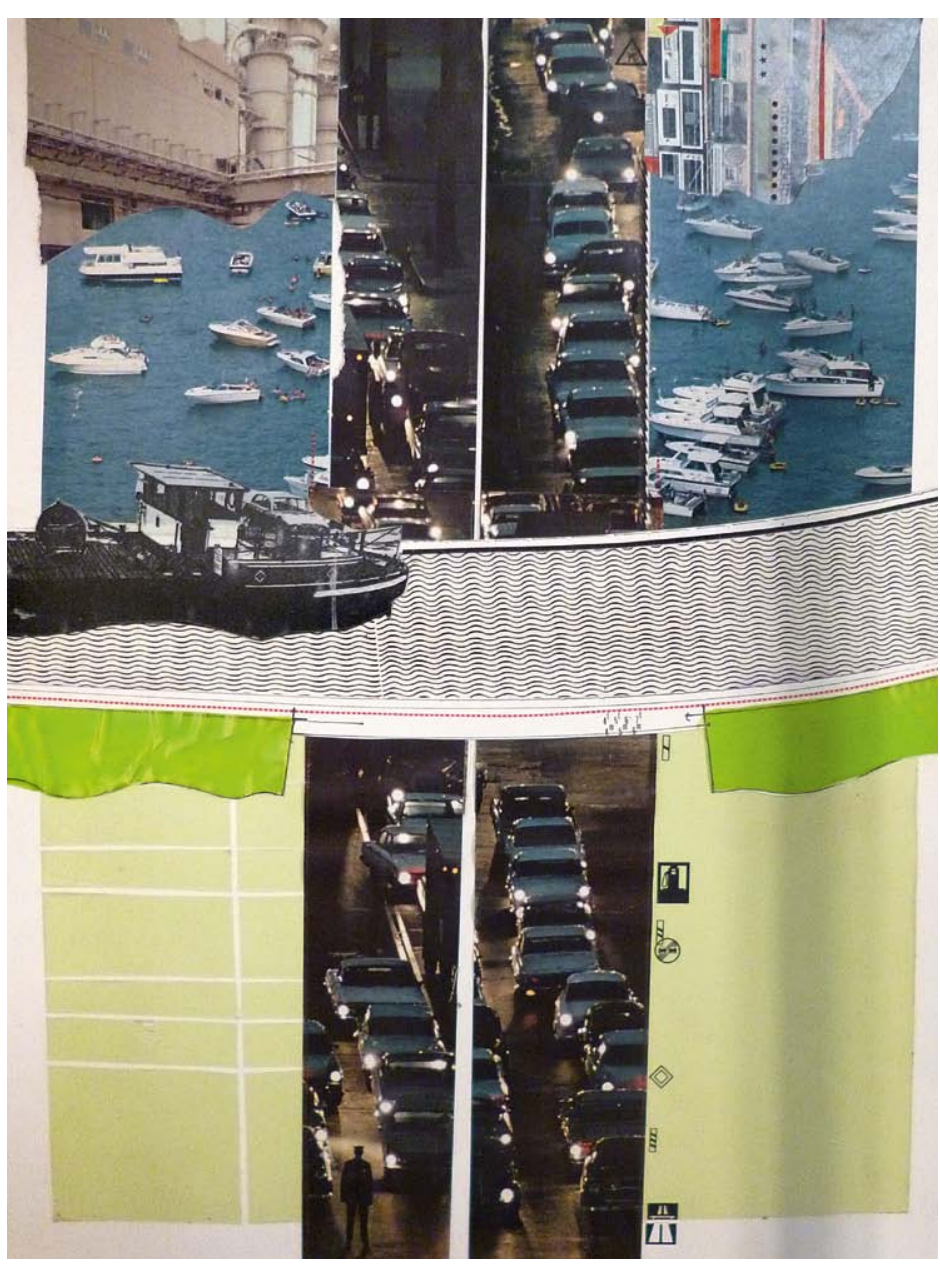

Figure 6 OMA / Rem Koolhaas: Haarlemmermeerpolder, 1986: "Crossing the Ringvaart" (collage, OMAR-NAi, Rotterdam)

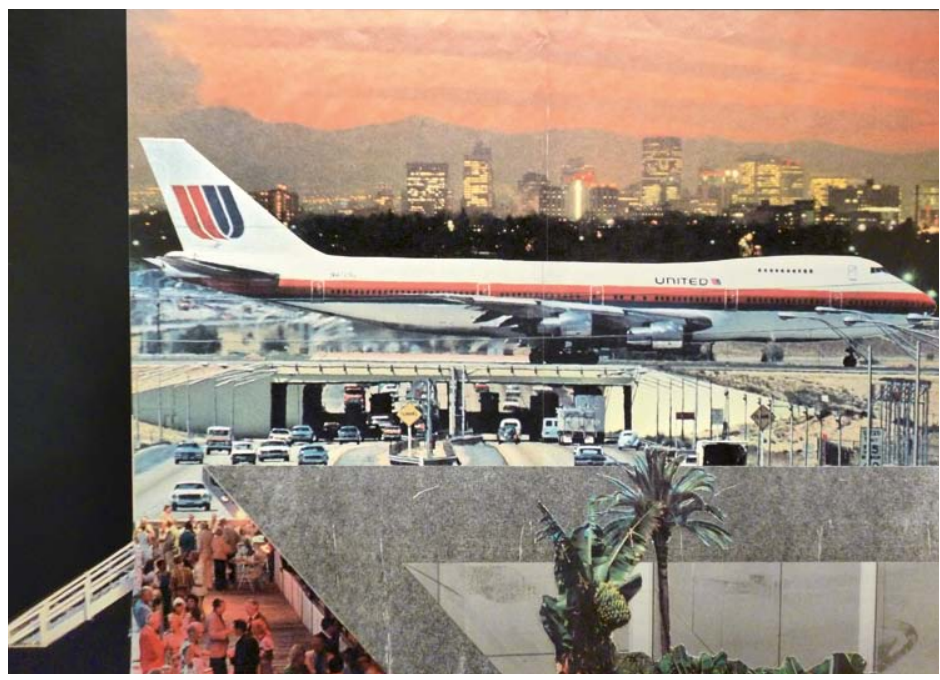

Figure 8 OMA / Rem Koolhaas: Haarlemmermeerpolder, 1986:

"Schiphol and the future skyline of Amsterdam" (collage, OMAR-NAi, Rotterdam) 


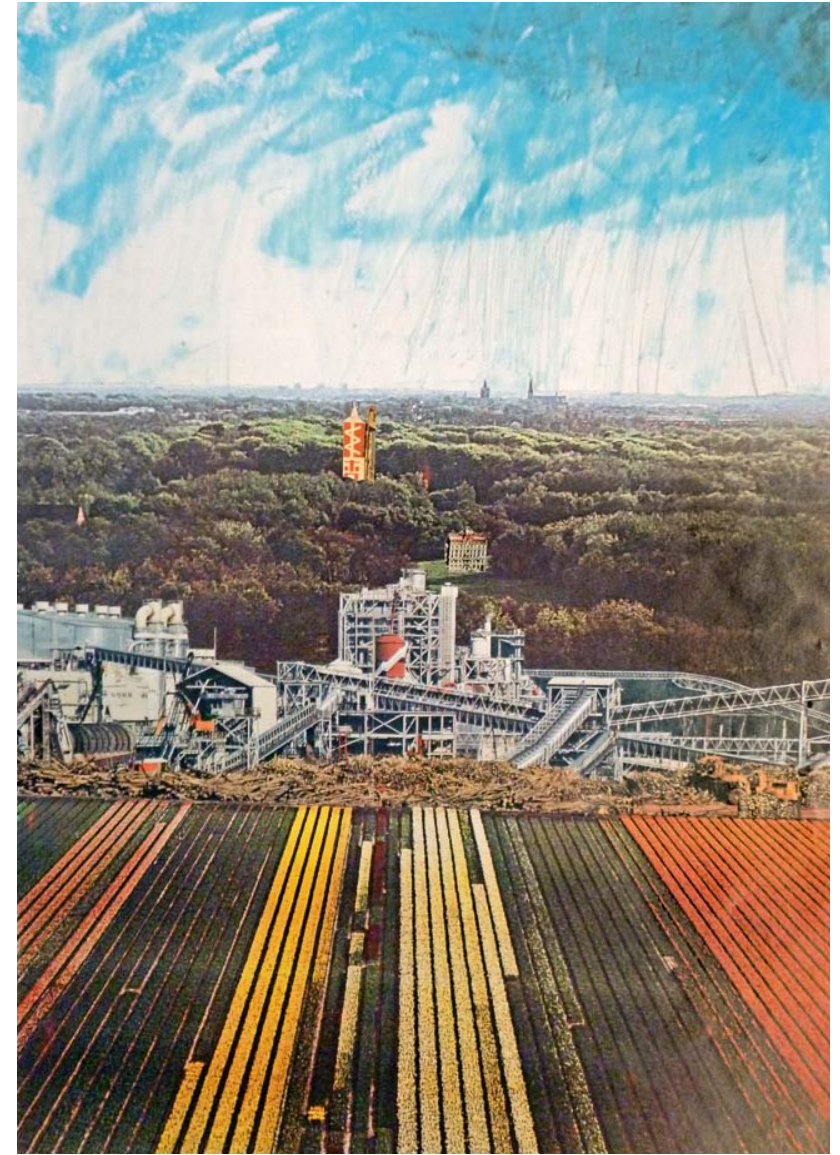

Figure 9 OMA / Rem Koolhaas: Haarlemmermeerpolder, 1986:

"Agricultural industry" (collage, OMAR-NAi, Rotterdam)

The collages present visualizations of this Dutch polder culture of congestion. One image shows how the true and refined cultivation and production processes take place inside, in the controlled climate of the greenhouse, where a small bird sips from a bottle of whiskey (Fig. 5). The entry to the Haarlemmermeerpolder is visualized as a tunnel under the Ringvaart: the busy highway continues, passing the newly inundated part of the polder, almost full with both recreational and industrial shipping (Fig. 6). Cars and trucks are, however, the most important means of transport: the highway intersects an industrial zone with, for example, a French fries factory (McCain), and on the other side, a warehouse full of books next to a garbage belt (Fig. 7). There is no mistake that Schiphol and Amsterdam are the most important destinations and that, as such, the Haarlemmermeerpolder is only a transit zone. "View at Amsterdam from Rick's', says the legend of one collage-a typical American roadside restaurant, bar, and service station (Fig. 8). The view on the possible skyline of the Dutch capital-a somewhat generic image of concentrated highrise development-is combined with that of a large jumbo jet. Only three images focus on the agriculture industry, although always in a montage with other seemingly incombinable functions and programmes, recreational or industrial in nature (Fig. 9), and once, via Haarlem and Zandvoort, connected to the North Sea (Fig. 10). Another somewhat puzzling collage shows David Byrne, lead singer of the Talking Heads, clad in a green jacket with feathers, as a 'young, rich farmer, Haarlemmermeer, 2000' (Fig. 11). Both the presence of airplanes and of an American Express credit card show that already in 2000, old-fashioned and real agricultural

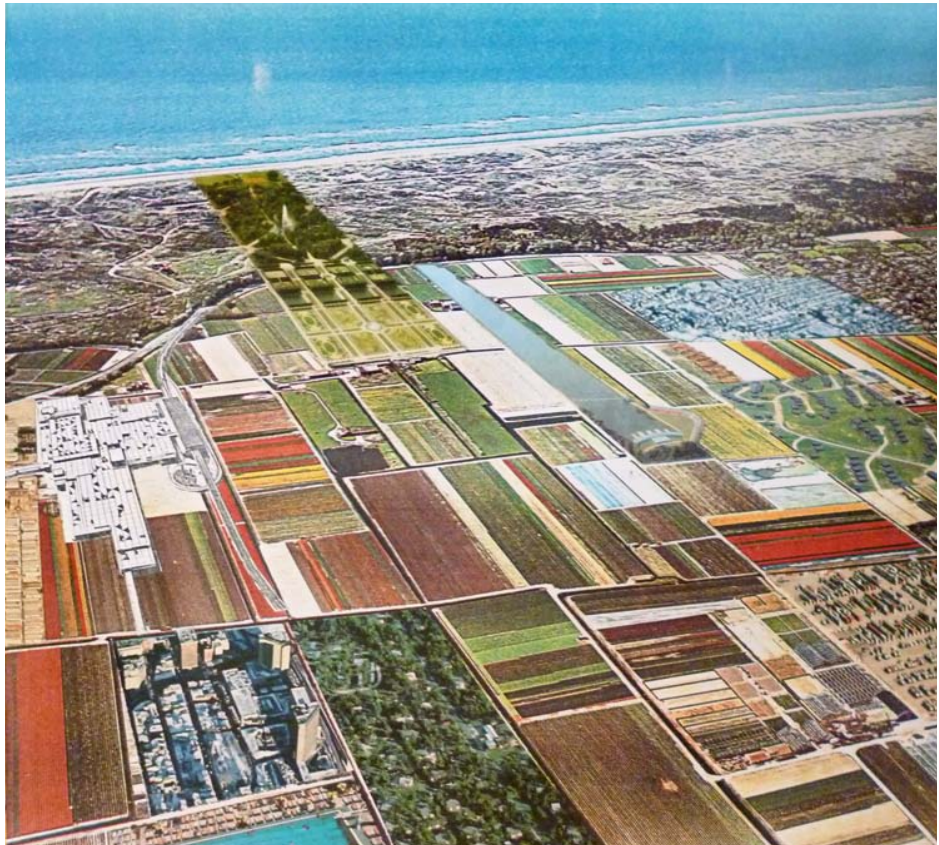

Figure 10 OMA / Rem Koolhaas: Haarlemmermeerpolder, 1986:

"A landscape grid towards the North Sea" (collage, OMAR-NAi, Rotterdam)

activities will no longer be very important. The true importance will lie in an economy of services, finances, and immaterial office labour, as exemplified in a set of four small collages, subtitled 'a Silicon Valley of commercial research and production centers in a fine-grained network of infrastructural provisions', Twin Towers with airplane included (Fig. 12).

At the time, the OMA proposal, and the corresponding polder landscape, received mixed responses. The editor of the NNAO catalogue wrote in a short text accompanying the design: 'The model is all things considered at first view a product of cheerful home craft. Without a doubt it will be very attractive to children and fools. Happily enough, work and work areas can still be exposed from an amusing, pleasurable side' (Van der Cammen 1987: 96). Dirk Frieling was more favorable, when he wrote in the Dutch newspaper NRC Handelsblad, dated 12 September 1987, about a recent road trip: 'After Schiphol, at the crossing of the road HoofddorpAalsmeer, I can already see the first start of the development that is colorized hard-handedly in the model of Koolhaas and Christiaanse. [...] You don't need to have fantasy for futuristic visions. You just need to see what is already happening today.' In Archis, Dutch critic Hans van Dijk commented on these remarks (and on the OMA design), by indicating that the designs made according to the dynamic scenario, were the most convincing: 'It is exactly from this corner that the wind blows in the eighties' (Van Dijk 1987:9). Two years later, the design was already considered a failure in the oeuvre of OMA-a judgment the office seems to agree on-regarding the absence of the project in retrospective publications, although it is still present on the OMA website project list. In 1989, on the occasion 


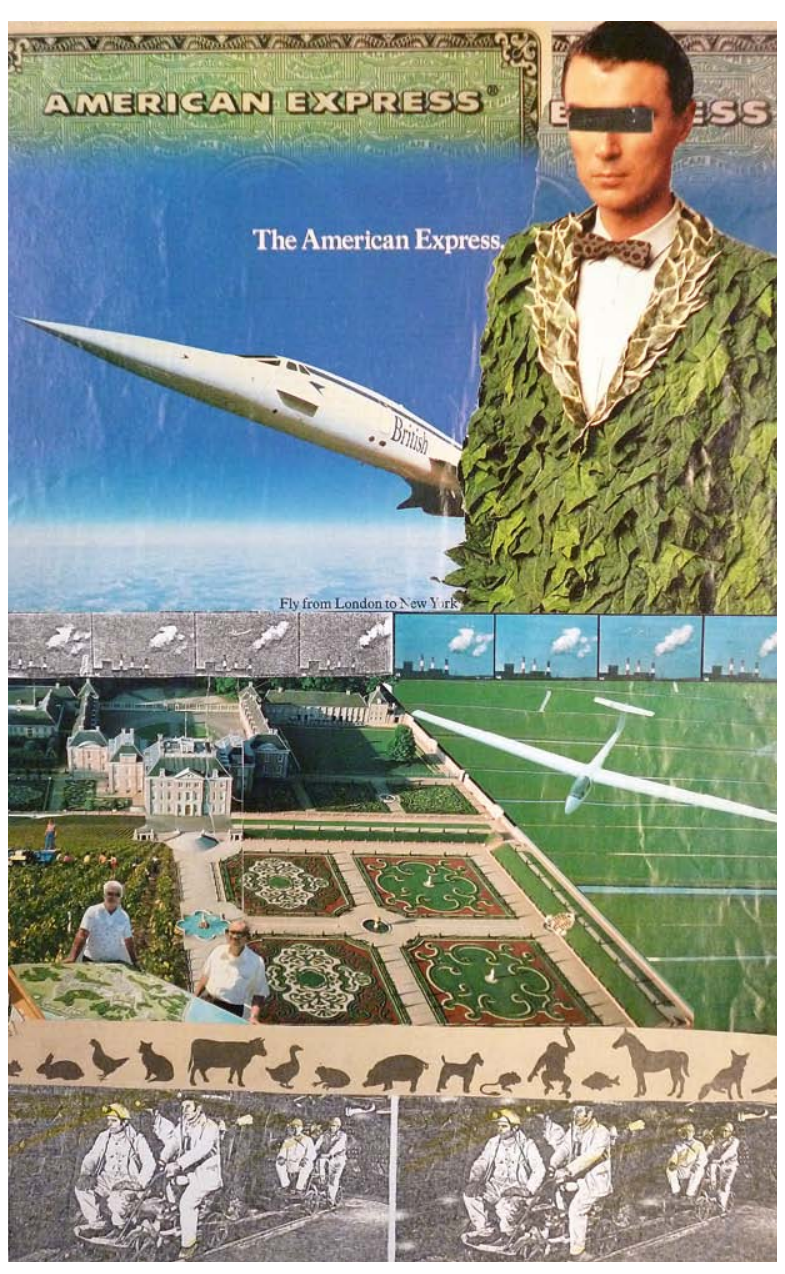

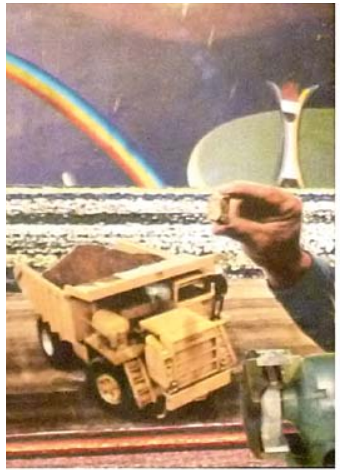
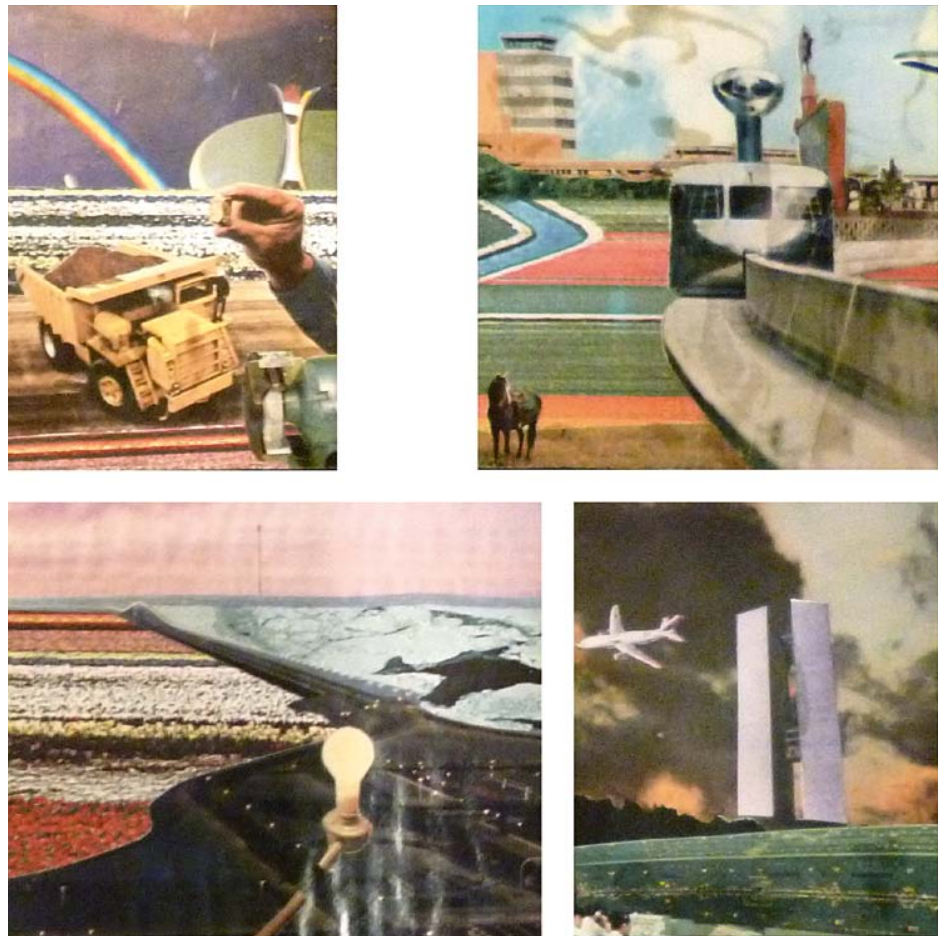

Figure 12 OMA / Rem Koolhaas: Haarlemmermeerpolder, 1986:

"Services, finances, and immaterial office labour" (collage, OMAR-NAi, Rotterdam)

Figure 11 OMA / Rem Koolhaas: Haarlemmermeerpolder, 1986:

"A young, rich farmer" (collage, OMAR-NAi, Rotterdam) of the retrospective exhibition The First Decade in Rotterdam, Koos Bosma wrote 'how in this project the imagination has shriveled to the opposite of a dynamic scenario. [...] Can Koolhaas do urbanism when he can no longer wander in his own figments?' (Bosma 1989: 50).

It is, however, from the contemporary, twenty-first century viewpoint, and in comparison with more 'classic' projects from the office, that the 1986 Haarlemmermeerpolder can reveal its true meaning and historic value. In Dutch New Worlds, Salewski hints in this direction, stressing how OMA did not offer a 'vivid image of the future', like most NNAO participants did: 'The model was rather a freeze-frame of continuous socioeconomic and spatial development based on an extrapolation of the existing structure' (Salewski 2010: 275). When considered within the historical context of two centuries of Dutch urban planning, and within the political and ideological climate of the 1980s, the design reveals itself as both a critique and as an affirmation. Like in other designs, OMA has concerned itself with the enlargement and the elucidation of the desires of their clients and of the society they belong to, sometimes with perverse or paradoxical results. The project was made at the instigation of NNAO, an association that wanted to revive the 'old' polder model in times when the political polder model made future-oriented urbanism impossible. OMA contradicted this: the model, the plans, and the collages from 1986 are images of what the polder landscape would look like if it really became the embodiment of polder politics_of the pluralist and bureaucratic worldview that is mostly striving for a flourishing economy, and that wants to solidify this objective in a broad-based consensus. Another sentence from the review of Parc de la Villette by Choay can easily be applied to the Dutch project of 1986: "It makes place for dialogue, for a host of major and minor decisions and choices to be made and argued in the course of time' (Choay 1985: 213). The landscape of the Haarlemmermeerpolder, as depicted by OMA, is a juxtaposition of all kinds of programmes that Dutch society considered worthwhile and important, with the economic and profitable activities at the front.

At the same time, it presents the audacity to consider the Dutch polder not as a natural given that needs to be protected and preserved, but as a cultural and historical construction that should constantly be questioned and, if necessary, transformed. Even more so: in the contemporary landscape of the polder, there is no longer any difference between nature and culture. That this is a condition that, according to OMA, transcends the Dutch territory is also something Choay has indicated with regard to Parc de la Villette: 'Greenery is used extensively. It is treated not only as a building material but almost mechanically: it symbolizes artificiality as it is made part of the general evolving system' (Choay 1985: 212).

As a whole, OMA's Haarlemmermeerpolder symbolizes the general system of the Netherlands at the end of the eighties. It seemed impossible to imagine a contemporary or future landscape for an individualized society stalled by the consensus model of the polder politics. But by increasing both the unity and the diversity of the Haarlemmermeerpolder, OMA both confirmed and transcended this stagnation. 
Conclusion: the public landscape of the Netherlands

The Haarlemmermeerpolder from OMA shows where the material and the symbolical landscape of Dutch society was coming from, where it was at the time, and where it was heading. At the same time, this 1986 project, made by the office so close to home, reveals the ideological and historical background of other OMA projects from the 1980s. Large empty areas, the vicinity of historical cities, the isolated but overwhelming presence of twentieth-century innovations, the collective desire for leisure and spectacle, and the suburban sprawl-all these elements are considered contrasts waiting to be revealed in the image of a European public landscape. As such, the desire for ground-breaking and large-scale public projects is reconciled with a diversified society, an immaterial economy, and a political system that seems to sabotage the possibility of a consciously created territory. Cunningly, and without being straightforward, OMA tried to explicate what happened, what was wanted, and what was possible.
The design did not influence the development of the Haarlemmermeerpolder, nor did it change the urban policy in the Netherlands. But despite everything, it was a precise and intentional 'imagining of landscape', that can be seen-in the words of Michiel Dehaene, Bruno Notteboom, and Hans Teerds in a recent issue of OASE on 'public landscapes'-'as an indication of a society's capacity to make the context in which it is given spatial form into the object of cultural reflection. Through this reflection of culture and through this imagination, a society's spatial form acquires meaning and is shared and mediated' (Dehaene, Notteboom, Teerds 2014: 5). To know where Dutch society is at right now, someone else should get started with the landscape of the Haarlemmermeerpolder.

\section{NOTES}

1 For a study of the conception of the Haarlemmermeerpolder, see: Jeurgens, C. (1991), De Haarlemmermeer: een studie in planning en beleid 1836-1858 (Amsterdam: NEHA). For an evolution of the area until the Second World War, see: Taverne, E. (2006), 'Het betwiste landschap van de Haarlemmermeer', BMGN-Low Countries Historical Review 121/4: 711-727.

2 For a recent history of Schiphol, see: Bosma, K. (ed.) (2013), Megastructure Schiphol. Design in spectacular simplicity (Rotterdam: NAi).

3 For the history of Almere, see for example: Brouwer, P. (1997), Van stad naar stedelijkheid: planning en planconceptie van Lelystad en Almere 1959-1974 (Rotterdam: NAi); Reijndorp, A. (ed.) (2007), Adolescent Almere. Hoe een stad wordt gemaakt (Rotterdam: NAi).

4 See for example: Koolhaas, R. (1985), 'La splendeur terrifiante du XXe siècle', L'Architecture d'Aujourd'hui 56/238: 15; Koolhaas, R. (1990), 'Tempo 160', Archithese 20/1: 39-43.

5 See for example: Van Gerrewey, C. (2013), “"Hope has returned”: The Glorious Reception of OMA / Rem Koolhaas in the Dutch-speaking World', Architectural Theory Review 18/3: 356-371.

6 The French original reads as follows: 'A la Villette [...], il semblait que toutes les conditions étaient réunies pour permettre une investigation des potentialités d'une architecture métropolitaine en Europe: un terrain vague entre la ville historique-elle-même "violée" par les demandes insatiables du XXe siècle-et le plancton de la banlieue'.

7 See also this recent ideological interpretation of the OMA designs for Paris in the 1980s: Aureli, P.V. (2015), 'Architecture and Counterrevolution. OMA and the Politics of the grands projets', OASE 35/94: 45-51.

\section{REFERENCES}

Bosma, K. (1989), 'De architect die leegte bouwde. OMA's stedebouwkundige concepten binnen het krachtenspel van de verstedelijking', Archis 4/3: 46-51.

Choay, F. (1985), 'La Villette Park Competition. Second Place Entry by the Office of Metropolitan Architecture', The Princeton Journal. Thematic Studies in Architecture: Landscape 1/2: 211-214.

Colenbrander, B. (1994), '1700 Aeroplanes a Day. Profile of a Busy Intermediate Area in the Randstad: The Haarlemmermeer Polder', Archis 9/4: 52-61.

Dehaene M., Notteboom B., Teerds H. (2014), 'Making Landscape Public / Making Public Landscape', OASE 34/93, 2-11.

Jonker, J., 'The Netherlands and the Polder Model', BMGN-Low Countries Historical Review 129/1: 88-89.

Koolhaas, R. (1985), 'La splendeur terrifiante du XXe siècle', L'Architecture d'Aujourd'hui 56/238: 15.

Lucan, J. (1990), OMA Rem Koolhaas: pour une culture de la congestion (Paris: Electa Moniteur).

Salewski, C. (2012), Dutch New Worlds. Scenarios in Physical Planning and Design in the Netherlands 1970-2000 (Rotterdam: 010 Publishers).

Van Dijk, H. (1987), 'Fundamenten van hoop en vrees. De toekomstscenario's van Nieuw Nederland', Archis 2/11: 8-9.

Van der Cammen, H. (ed.) (1987), Nieuw Nederland: onderwerp van ontwerp ('s Gravenhage: Staatsuitgeverij).

\section{BIOGRAPHICAL NOTES}

Christophe Van Gerrewey (1982) is an architectural and literary theorist. In 2014, he obtained his $\mathrm{PhD}$ at Ghent University in Belgium, with a study of the writings of architecture critic Geert Bekaert. He has published in journals such as Architectural Theory Review, Journal of Architecture, $A+U$, and $2 G$. In 2014, he wrote a critical history of Belgian architecture since 1989 (Architecture en Belgique. 25 années en 75 projets). He is co-editor of an issue of OASE on 'the First Decade' of OMA / Rem Koolhaas, published in April 2015. As of September 2015, he is Assistant Professor Theory of Architecture at EPFL in Lausanne, Switzerland.

\section{CONTACT}

Christophe Van Gerrewey Assistant Professor Theory of Architecture EPFL ENAC

Station 16

CH-1015 Lausanne, Switzerland 